Proceedings of the 2nd International Congress APMAS2012, April 26-29, 2012, Antalya, Turkey

\title{
Study of the Relation between Microstructure and Properties (Mechanical/Electrical) of Copper Wire Drawing and Annealed
}

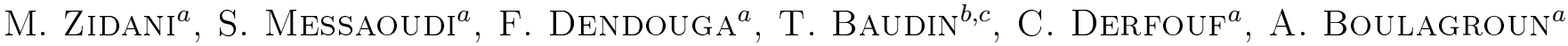 \\ AND M.H. MATHON ${ }^{d}$ \\ ${ }^{a}$ Laboratoire de Génie Energétique et Matériaux, Lgem, Université de Biskra - B.P: 145, Biskra 07000, Algeria \\ ${ }^{b}$ CNRS, UMR8182, ICMMO, Laboratoire de Physico-Chimie de l'etat Solide, Orsay, F-91405, France \\ ${ }^{c}$ Univ Paris-Sud, Orsay, F-91405, France \\ ${ }^{d}$ Laboratoire Léon Brillouin, CEA(DSM-DRECAM)-CNRS, CEA Saclay, 91191 Gif sur Yvette, France
}

\begin{abstract}
The aim of this study is to clarify the relation between microstructure and properties (hardness and electrical resistivity) of copper wire drawing by the ENICAB Company and distended for electrical cabling. In this work we studied the evolution of the microstructure and (mechanical/electrical) properties of the wire drawn and annealed at $260^{\circ} \mathrm{C}$. The drawing causes anisotropy structural that result in an elongation of grains along the axis of drawing. There was also an increase in electrical resistivity and in hardness following the deformation level increases. After annealing at $260^{\circ} \mathrm{C}$ of the drawn wire, it was found a gradual return of the mechanical properties and microstructure to a state close to the state of as-received copper.
\end{abstract}

DOI: $10.12693 /$ APhysPolA.123.470

PACS: $81.30 . \mathrm{Hd}$

\section{Introduction}

The drawing is to reduce the section of a wire by passing through one or more dies, under the effect of a tensile force (stretching). It is generally followed by a recrystallization annealing. Structural changes entrained by cold plastic deformation alter physical and mechanical properties of metals.

This work is devoted to the study of the combined effect of the deformation and annealing temperature on microstructure and mechanical and electrical properties of copper wire. ENICA Biskra Company uses the drawing process on several types of as-received wire of different materials and shades. In our study, we opted for the copper wire electrolytic tough pitch (ETP). These wires produced by this company are designed to meet the needs of the Algerian market in electric cables.

\section{Material studied and methods of characterization}

In our study, we opted for the as-received wire copper $(\mathrm{Cu}$ minimally $=99.26 \mathrm{wt} \%)$ electrolytic tough pitch (ETP-1) initial diameter of $8 \mathrm{~mm}$ and of three different wires diameters which represent three different deformation $\left(\varepsilon_{1}=47.97 \%, \varepsilon_{2}=71.64 \%\right.$ and $\left.\varepsilon_{3}=91.66 \%\right)$ from a line drawing of eleven sectors, all these wires were provided by the ENICAB company (Biskra, Algeria). Characterization methods used in this study are: optical and electron microscopy, microhardness, resistivity measurement and tensile test microstructure of drawn wires.

The microstructures (Fig. 1) show as-received wire form equiaxed grains. However, in the longitudinal plane
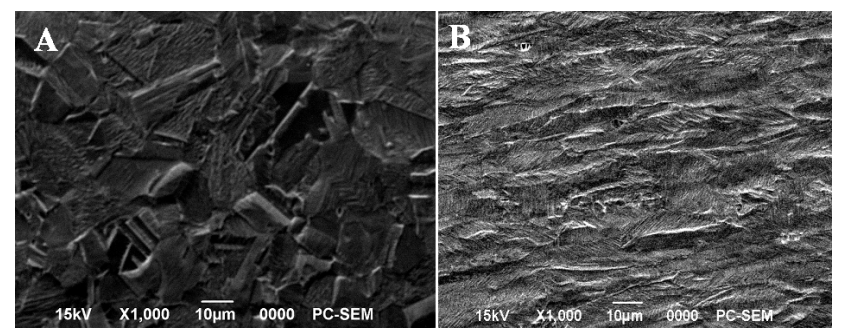

Fig. 1. SEM microstructures of as-received copper (A) and drawn wire $\left(\varepsilon_{2}=71.64 \%\right)(\mathrm{B})$.

of the drawn wire, there is a microstructure of elongated grains along the axis of drawing (Fig. 1b). According Zidani et al. $[1,2]$ depending on whether the level of deformation increases, the drawn wire acquires a textured fibrous microstructure. This texture is frequently observed in the wires drawing and is known as the texture of fiber or fibrous texture, because it resembles the arrangement of a fibrous material. A structural scale is merely for an orientation in a direction parallel to well-defined crystallographic axis of the wire. This texture is symmetrical about the axis of the wire, known as the (fiber axis). Microhardness measurements show an increase in the hardness of the drawn wires with the deformation level. This increase is very strong in the first stage of the deformation and then tends to stabilize (Fig. 2). This type of result has already been met on the steel wire drawing [3,4]. This hardening is interpreted by the hardening mechanism, leading to a very high dislocation density in the deformed material. 


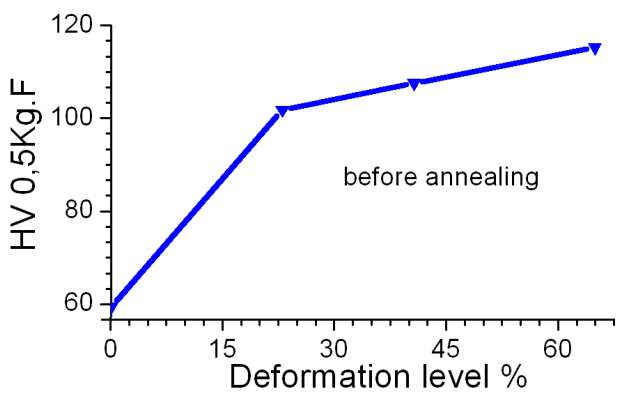

Fig. 2. Vickers microhardness curve of the copper wire after cold wire drawing.

\section{Study of the annealed drawn wires}

The mechanism of recrystallization is triggered just after the first minute hold $(9 \mathrm{~min})$ to $260^{\circ} \mathrm{C}$ in particular wire strongly deformed (Fig. 3a). The latter structures develop over the extended holding time (Fig. 3b). This result is consistent with various studies and theories of recrystallization, as a large plastic deformation leads to a large energy stored in the drawn wires by means of a large number of dislocations, which causes the onset of recrystallization mechanism $[5,6]$. The curves of microhardness show a softening for all drawn wires and annealed at $260^{\circ} \mathrm{C}$, this decrease is larger for the weakly deformed wire (Fig. 4).

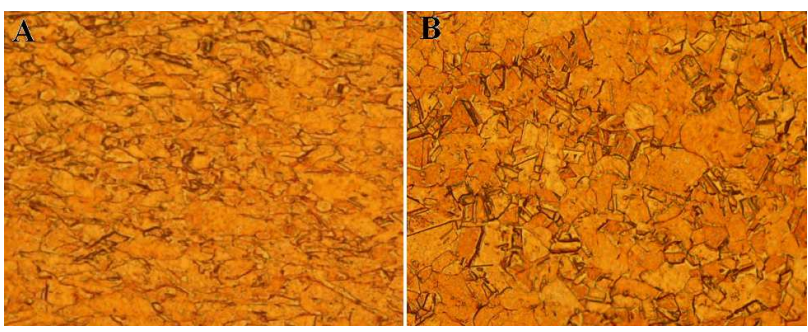

Fig. 3. (OM) Microstructure (500×) of copper wire after deformation $\left(\varepsilon_{3}=91.66 \%\right)$ and isothermal annealing during: (A) $(9 \mathrm{~nm})$, and (B) $(30 \mathrm{~nm})$ at $260^{\circ} \mathrm{C}$.

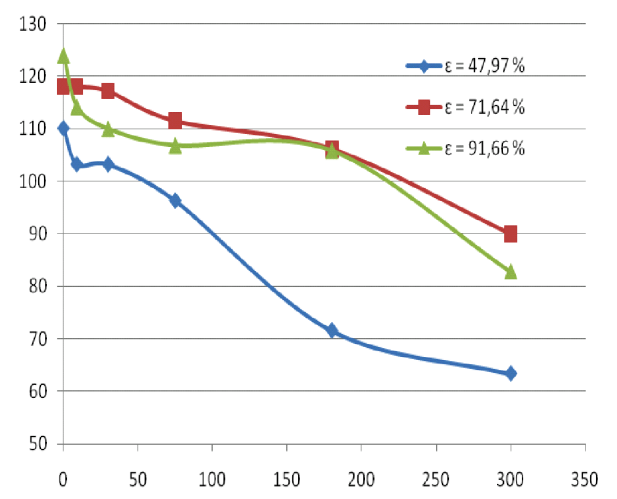

Fig. 4. Evolution of the mean value of the hardness as a function of holding time.

\section{Tensile test and measurement of the electrical resistivity}

The resistivity measurements and tensile test were made at the physics laboratory of ENICAB-Company (Algeria) for the drawn wires and then after annealing at $260^{\circ} \mathrm{C}$. The results of tensile tests (as-received/deformed) before and after annealing presented in Table clearly show the return of all mechanical properties to a state close to the state of the as-received wire.

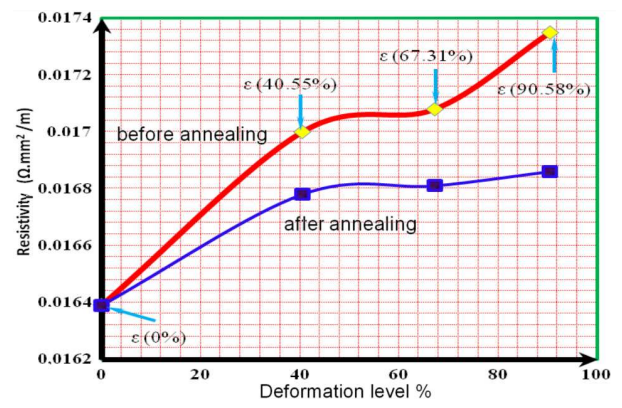

Fig. 5. Resistivity measurements for the copper wire before and after annealing at $260{ }^{\circ} \mathrm{C}$ (Physics Laboratory - ENICA, Biskra).

TABLE

Results of tensile tests before and after annealing.

\begin{tabular}{c|c|c|c|c}
\hline \hline \multirow{2}{*}{$\varepsilon[\%]$} & \multicolumn{2}{|c|}{ Before annealing } & \multicolumn{2}{c}{ After annealing } \\
\cline { 2 - 5 } & $\mathrm{A}[\%]$ & $R_{m}\left[\mathrm{~N} / \mathrm{mm}^{2}\right]$ & $A[\%]$ & $R_{m}\left[\mathrm{~N} / \mathrm{mm}^{2}\right]$ \\
\hline 0 & 39 & 235 & 39 & 233 \\
47.97 & 4.0 & 322 & 40 & 239 \\
71.64 & 2.5 & 414 & 38 & 245 \\
91.66 & 2.0 & 464 & 38 & 253
\end{tabular}

The results of the resistivity before and after annealing at $200^{\circ} \mathrm{C}$ are illustrated in Fig. 5. We note a clear increase in resistivity with the reduction rate by drawing. On the other hand, annealing at $260^{\circ} \mathrm{C}$ for 30 min maintaining caused a slight decrease in resistivity by porting the state drawn $[7,8]$. This result is in conformity with the results of Cetinarslan [9] on the effect of deformation on electrical conductivity of copper and those of Niewczas et al. [10] on deformed copper. The calcutation of resistivity evolution exhibits an increase in resistivity of $1.7 \%$ between the $28.59 \%$ and $84.59 \%$ reduction level. Related to the previous studies [11], it was found that deformed $\mathrm{Cu}$ contains a high density of dislocations and also small vacancy clusters formed by the agglomeration of deformation-induced vacancies. The presence of these defects is barriers (the well) against the movement of electrons in the metal [12].

\section{Conclusion}

The study of industrial copper wire drawn and annealed, allowed us to deduce the following conclusions: 
- The drawing causes development a fiber texture accompanied by an increase in hardness with the deformation.

- The annealing leads to recrystallization especially for strong deformations with a return of all mechanical properties to a state close to the state of the as-received wire.

- An increase in resistivity with the reduction level by drawing.

- The annealing at $200^{\circ} \mathrm{C}$ for 30 min holding causes a slight decrease in resistivity by porting state drawn.

\section{References}

[1] M. Zidani, Z. Boumerzoug, T. Baudin, R. Penelle, Mater. Sci. Forum 514-516, 554 (2006).

[2] M. Zidani, Z. Boumerzoug, T. Baudin, D. Solas, Mater. Sci. Forum. 550, 447 (2007)

[3] M. Zidani, S. Messaoudi, T. Baudin, D. Solas, M.H. Mathon, Int. J. Mater. Form. 3, 7 (2010)
[4] Z. Boumerzoug, N. Lahraki, M. Zidani, Mater. Sci. Forum. 467-470, 235 (2004).

[5] S. Jakani, T. Baudin, C.-H. de Novion, M.-H. Mathon, Mater. Sci. Eng. A 456, 261 (2007)

[6] S. Jakani, PhD. Thesis, University Paris XI, 2004.

[7] M. Zidani, S. Messaoudi, C. Derfouf, A. Boulagroun, M.H. Mathon, T. Baudin, AIP Conf. Proc. 1400, 579 (2011)

[8] N. Takata, S.H. Lee, N. Tsuji, Mater. Lett. 63, 1757 (2009)

[9] S. Çetinarslan, Mater. Design 30, 671 (2009)

[10] M. Niewczas, O. Engler, J.D. Embury, Acta Mater. 52, 539 (2004)

[11] G. Mohamed, B. Bacroix, Acta Mater. 48, 3295 (2000).

[12] C. Kittel, Physics of Solids, Dunod, Paris 1998 (in French). 